Research Note

\title{
A Battery Powered Highly Efficient Exterior Lighting System Using Low Pressure Sodium Vapour Lamp for Use in Non-electrified Areas
}

\author{
Kalyankumar RAY*, Sujit GOLDER ${ }^{* *}$ and Saswati MAZUMDAR** \\ *Department of Instrumentation \& Electronics Engg., Salt Lake Campus, \\ Jadavpur University, Kolkata-700098, India \\ **Electrical Engg. Department, Jadavpur University, Kolkata-700032, India
}

Received May 16, 2006, Accepted September 21, 2006

\begin{abstract}
Innumerous attempts to solve the problems of exterior lighting in non-electrified areas of India e.g. highways, hilly areas, rural areas of delta regions have been made in the last two decades. A solar powered lighting system with 11 watt or 18 watt Compact Fluorescent Lamps (CFL) have been mounted in street light fixtures at some places ${ }^{1}$ but insufficient amount of light do not always serve the required need of the users specially in foggy weather. This paper reports the development of a battery powered lighting system fitted with a 35 Watt Low Pressure Sodium Vapour (SOX) lamp. It is extremely beneficial in remote nonelectrified areas for its far higher light output when fitted in street light or flood light fixtures. The battery may be charged from any non-conventional energy source and is connected to the electronic circuit, which operates at high frequency. The light output of this system fitted with a solar photovoltaic array (SPVA) and the corresponding battery power have been measured and the results have been reported in this paper. This high intensity lighting system has a wide application potential in developing countries throughout the world.
\end{abstract}

\section{KEYWORDS: energy-efficient, battery-powered, DC electronic ballast, SOX lamp}

\section{Introduction}

The origin of the sodium vapour lamp may be traced back to a 1919 patent taken out by Arthur H. Compton of Westinghouse Electric in the U.S.A. This was the first light source, which radiated the characteristic deep yellow sodium resonance lines (Compton, 1919). Compton had noted that the sodium discharge delivered a remarkably high luminous efficacy of more than $200 \mathrm{~lm} / \mathrm{W}$, although this figure did not include the power required to heat the lamp to its operating temperature (Compton and van Voorhis, 1923). In 1920 Compton made the first successful sodium vapour lamp based on borated glass. In 1930, M. Pirani of the German Osram company, noticed that low voltage high current tubular lamps required pressure to vaporise the sodium at a pressure of $10 \mathrm{~Pa}$ in krypton-filled tubes ${ }^{2}$.

The first practical sodium lamp light source was created following Pirani's work in August 1931. The efficacy of that low pressure sodium lamp was $46 \mathrm{~lm} / \mathrm{W}$. The efficacy of the future lamp was improved upon and it was found that the efficacy of the low pressure sodium lamp increased proportionally with the lamp power. The principal reason for the high efficacy is because of the yellow colour of the lamp light which is close to the maximum sensitivity of the human eye in normal viewing conditions.

The other advantages of the modern low pressure sodium vapour (SOX) lamp which prompted its use in rural exterior lighting system are listed below ${ }^{344)}$ :

1. This lamp being most efficient light source available till now, it can deliver more light output than any other lamp of same wattage.

2. The physical size of the lamp being large, it has low luminance, so it is less likely to give rise to glare.

3. The low operating temperature permits the use of compact optical systems and lightweight plastic lanterns.

4. The long lamps may be aligned end-to-end to produce a continuous line of light and this almost totally eliminates the stroboscopic effect.

5. This lamp contains no mercury and so it is easily disposable.

6. The striking voltage is not sensitive to temperature as is the case for many other discharge lamps.

7. In the case of momentary power supply interruption, the lamp restrikes as soon as the power is restored.

8. This lamp can be used in foggy weather. The mono- 
chromatic ( $589 \mathrm{~nm}$ wavelength) rays of SOX source is not dispersed easily in droplets of water unlike the light from other sources. Thus the images received by the human eye in the fog are always sharp and clear.

For the above advantages SOX lamp has been chosen for exterior lighting notwithstanding its poor colour rendering capability.

It is necessary to illuminate the roads, jetties, forest pathways, and sea shores with the non-conventional energy sources. To solve this problem a solar energy based 12 volt battery powered electronic ballast and control gear circuit have been developed. It is an inverter circuit with an automatic control and timing circuit for artificial illumination with a $35 \mathrm{~W}$ SOX lamp. The circuit is fed by a storage battery, which, in turn, is charged by a solar photovoltaic array (SPVA). The arrangement consists of a $35 \mathrm{~W}$ SOX lamp mounted in a luminaire on a pole. Two $100 \mathrm{WP}$ (peak watts) SPVA mounted on the top of a 3.7 meter high 3 -segment pole charges the $160 \mathrm{AH}$ storage battery fitted in the middle segment of the pole.

\section{Description of the system}

\subsection{Block diagram description}

The block diagram of the proposed system is shown in Fig.1. The functional blocks of the block diagram are:

1. Solar photovoltaic array (SPVA).

2. A12-Volt lead-acid storage battery.

3. An inverter power circuit.

4. A control circuit.

5. ASOX Lamp.

The inverter power circuit is powered from battery voltage which produces the high frequency voltage for running the $35 \mathrm{~W}$ SOX lamp. The inverter output fre- quency $\mathrm{f}$ is approximately $41 \mathrm{kHz}$. At sunrise, power to the lamp is automatically switched off.

The control block is connected to SPVA. It senses twilight and sets the lamp in turn on condition and at dawn the lamp turns off automatically. The necessary supply voltages for this circuit come from battery.

\subsection{Inverter power circuit}

The inverter power circuit is a MOSFET based circuit The block diagram of inverter power circuit is shown in Fig.2. The positive side of SPVA is connected through a low-cost dual Schottky diode D1 with the positive side of 12 volt battery to give high efficiency for charging the circuit.

The inverter circuit is powered from a 12 volt battery through a fuse $\mathrm{F} 1$. The inverter drive signal is generated by U1 (TL 494), an easily available pulse-width modulation (PWM) IC ${ }^{5}$. The outputs of the U1 are high frequency square wave which is fed to the inverter made with two parallel pair of MOSFET Q3, Q4, to feed the lamp load. The centre tap of the primary side of a transformer $\mathrm{T} 1$ is connected with the inverter. The centre tap of the primary side of $\mathrm{T} 1$ is connected with a

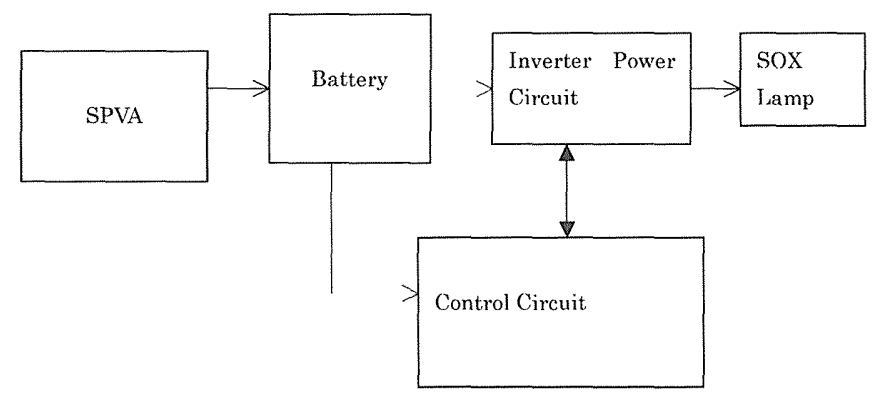

Figure 1 Block diagram of the system

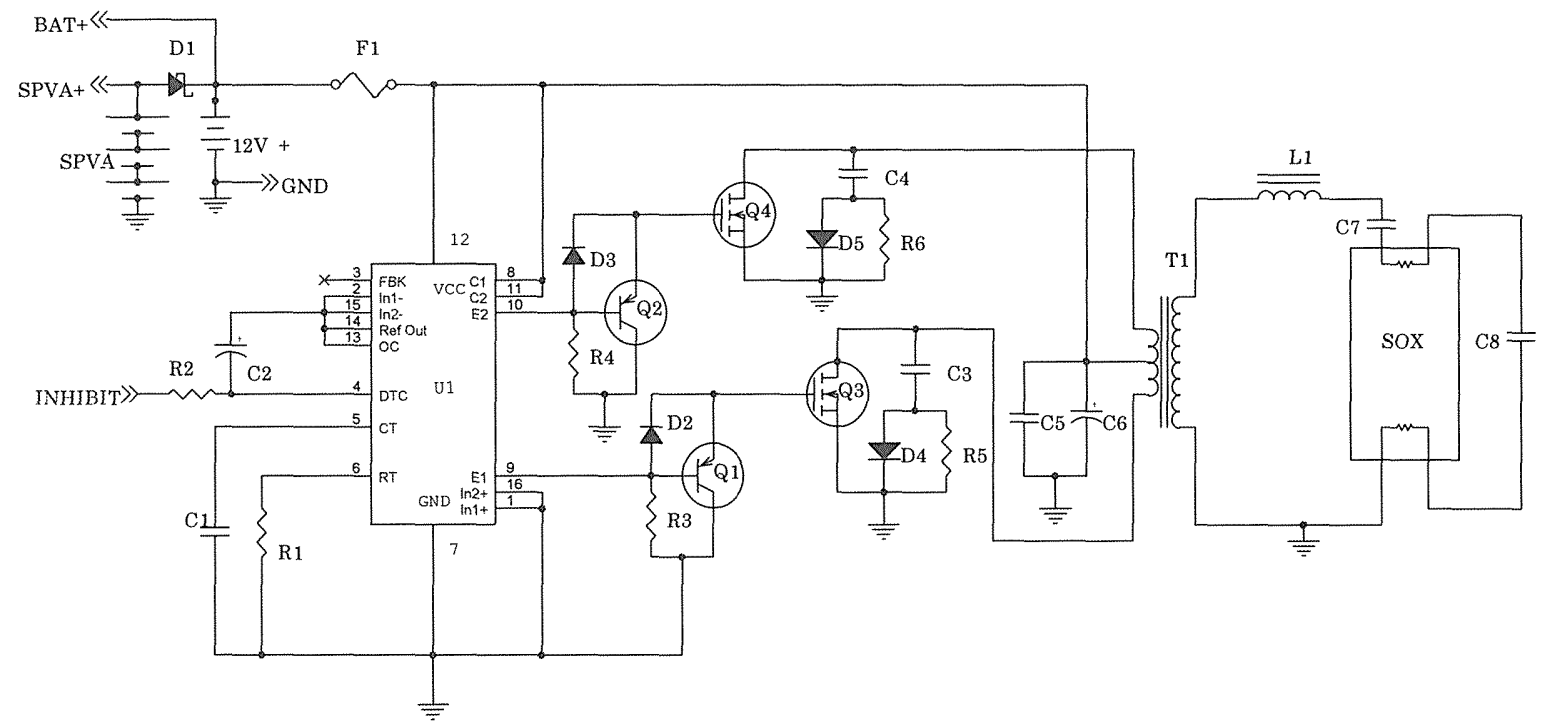

Figure 2 The inverter power circuit block diagram 
capacitor C6 that prevents excessive heating of the MOSFET and transformer core winding of the circuit. The secondary of $\mathrm{T} 1$ is connected with a current limiting inductor L1, and ignition capacitor C8 in parallel with the lamp electrode and $\mathrm{C} 7$ in series with them, thus a series $R-L-C$ resonant tank is formed which gives a high frequency resonance voltage to ignite the lamp. The series capacitor blocks the harmonic components, which prevent the excessive heating of the transformer core and winding. After sun set, the proposed circuit switches on automatically and ignites the lamp.

The inverter output frequency being nearly about 41 $\mathrm{kHz}$ (approximately), is half of the oscillator frequency. This frequency is determined by the external components RT (R1) and CT (C1). The approximate oscillator frequency is determined by:

\section{fo $=1.1 / \mathrm{RT}^{*} \mathrm{CT}$}

At dawn, when the sun rises, the INHIBIT signal comes from the control circuit and lamp is automatically switched off, till the next twilight signal comes from the control circuit.

\subsection{Control circuit}

The control circuit block diagram is shown in Fig.3. The control block connected to SPVA consists of a day light presence (DLT) and absence detector and a battery low voltage detector (LOBAT) and a +5 volt regulator. From the battery, a regulated +5 volt is generated by a three terminal voltage regulated IC U2 (LM 7805). The control circuit senses the twilight and lowers the INHIBIT signal. This starts the inverter and sets the lamp to on state. The necessary supply voltages for this circuit come from battery.

The DLT signal is obtained from a comparator U3a (1/4 of LM 339) and U4a (1/4 of CD 4011). To avoid the false triggering the DLT signal is fed back through a NAND gate U4b (1/4 of CD 4011). There is also a provision for manual switching off, which is done by U5b (1/4 of CD 4071). To protect the battery from discharging with too low terminal voltage (deep discharge condition) the system senses a LOBAT condition through U3b ( $1 / 4$ of LM339) and turns off the inverter by U5a (1/4 of CD 4071). The electronic shutdown signal (INHIBIT) is generated by OR-ing the DLT, LOBAT signals and a manual off signal obtained from a switch.

In the daytime if the sky is heavily overcast, the lamp may turn on automatically and glowing. In the night, in stormy weather if lightning flashes occur, transient increase of the SPVA voltage is suitably filtered by capacitor $\mathrm{C} 10(100 \mu \mathrm{F})$ and $\mathrm{C} 11(100 \mathrm{nF})$ so that a spurious turn-off of the lamp does not occur.

\section{Study of important waveforms}

A calibrated digital storage oscilloscope was used for the experimental studies. The waveforms have been stored and analyzed with the help of appropriate software. A non-contact current probe with a scale factor of $100 \mathrm{mv} / 100 \mathrm{~mA}$ was used for current measurement.

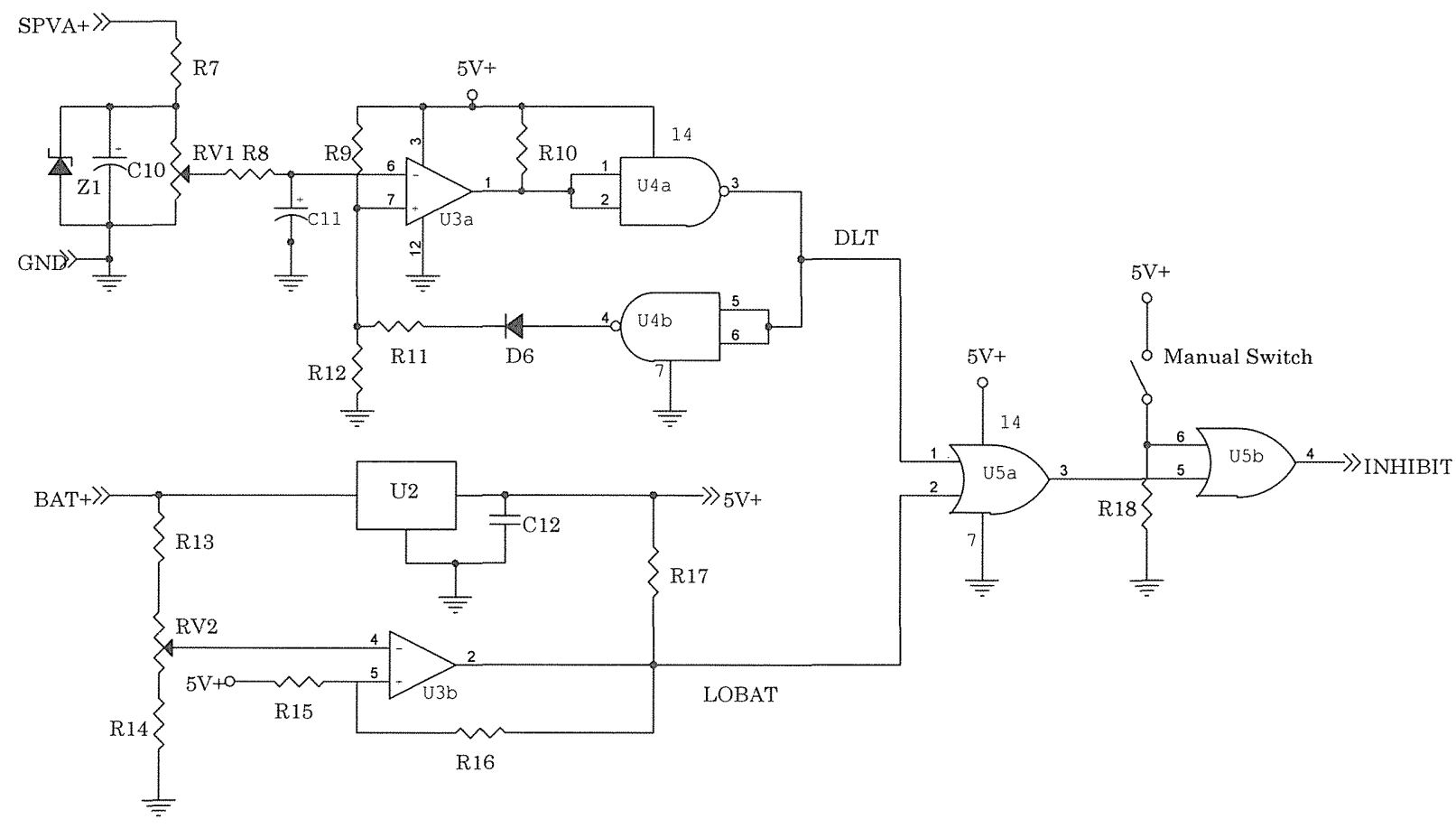

Figure 3 Control circuit block diagram 
The various types of waveforms obtained from magnetic ballast and the battery powered dc electronic ballast (lamp and transformer secondary) in running condition have been studied.

\subsection{Lamp voltage and current waveforms for dc elec- tronic ballast}

The lamp voltage and current waveforms are shown in Fig.4. Channel 1 represents the lamp voltage waveform and channel 2 represents the current waveform. The lamp voltage is found $236 \mathrm{~V}$ ( $\mathrm{pk}$ to $\mathrm{pk}$ ) and the lamp current is found $1440 \mathrm{~mA}$ (pk to $\mathrm{pk}$ ). Both the waveforms are approximately sinusoidal.

3.2 Transformer output voltage and lamp voltage waveforms for dc electronics ballast

Fig.5 shows the transformer secondary output voltage and the lamp voltage. Channel 1 represents the trans-

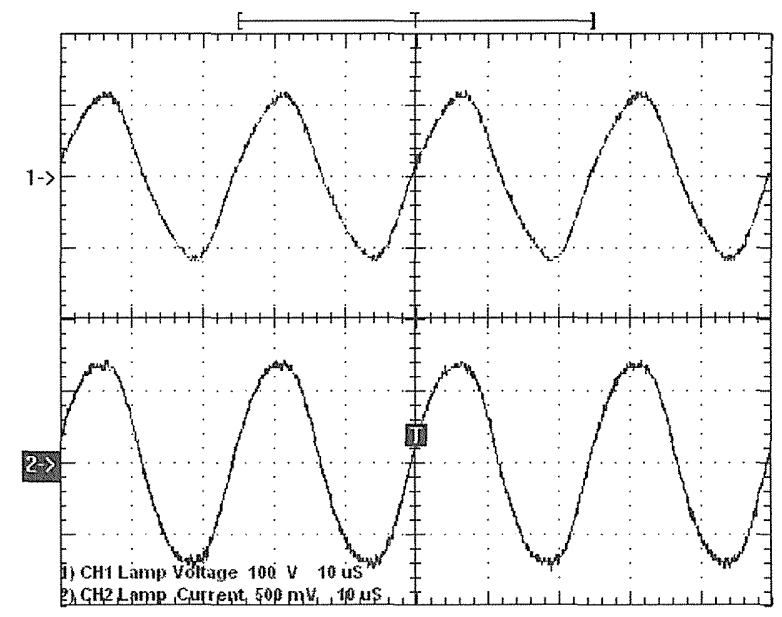

Figure 4 Lamp voltage and current waveforms for dc electronic ballast

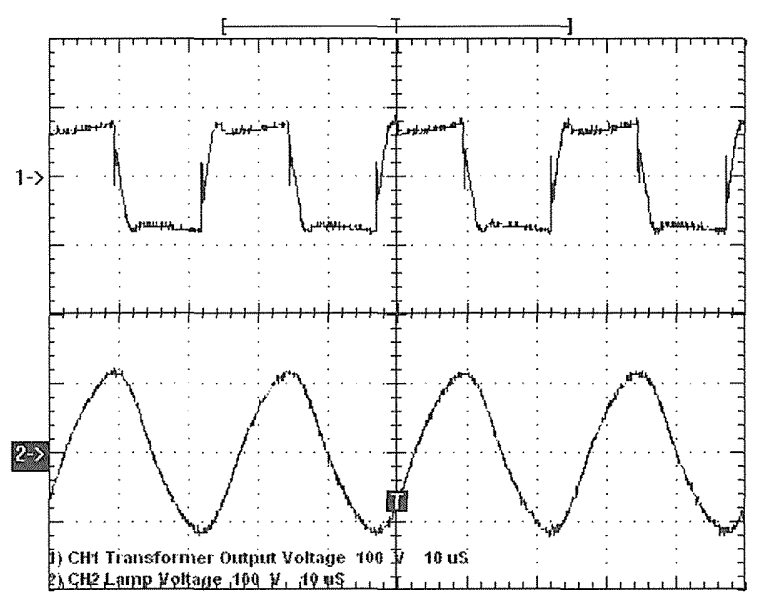

Figure 5 Transformer output voltage and lamp voltage waveforms for dc electronic ballast former secondary voltage, which is $160 \mathrm{~V}$ (pk to $\mathrm{pk}$ ) and channel 2 represents the $236 \mathrm{~V}$ (pk to $\mathrm{pk}$ ) lamp voltage. The secondary voltage is approximately square in nature.

3.3 Supply voltage and lamp current waveforms for magnetic ballast

The 240 volt supply voltage and lamp current waveforms are shown in Fig.6. Channel 1 represents the supply voltage and channel 2 represents the lamp current. The phase difference between supply voltage and lamp current is $81^{\circ}$. Thus the input power factor for magnetic ballast is 0.156 which is very low.

3.4 Lamp voltage and lamp current waveforms for magnetic ballast

The lamp voltage and lamp current for magnetic ballast are shown in Fig.7. Channel 1 represents lamp

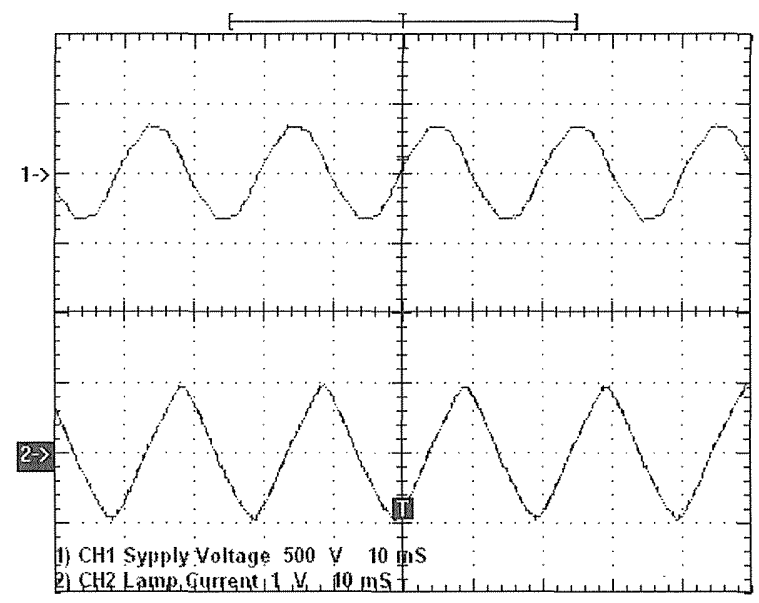

Figure 6 Supply voltage and lamp current waveforms for magnetic ballast

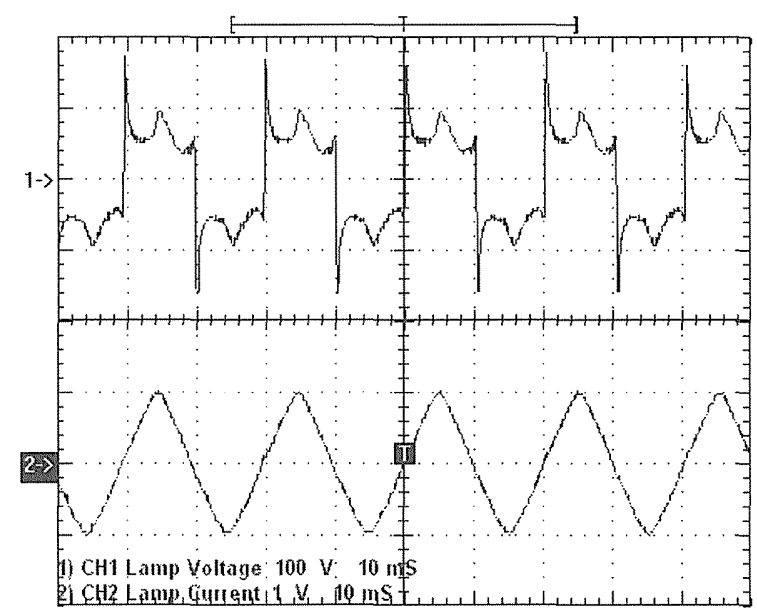

Figure 7 Lamp voltage and lamp current wave form for magnetic ballast 
voltage waveform and cannel 2 represent lamp current waveform.

The lamp voltage is $145 \mathrm{~V}$ (pk to $\mathrm{pk}$ ) and the lamp current is $2 \mathrm{~A}$ (pk to $\mathrm{pk}$ ). While the lamp current is nearly sinusoidal, the lamp voltage is a highly distorted square wave. The lamp voltage and current waveforms are in nearly same phase.

\section{Experimental data and calculation}

With the Oscilloscope and the software the harmonics calculations were performed both with magnetic ballast (supply voltage ac $240 \mathrm{~V}$ ) and dc (12V) electronic ballast connected to four lamps-A1, A2 manufactured by company $\mathrm{A}$ and other two by $\mathrm{B}$ and $\mathrm{C}$ company respectively. The Table1 shows current, input power voltage THD (Total Harmonics Distortion) current THD for all combinations of the lamp and ballast available.

From Table 1 the voltage harmonics distortions in

Table 1 Electrical characteristics for Magnetic(Mag.) and DC Electronics(Elec.) ballast

\begin{tabular}{|c|c|c|c|c|c|c|c|c|}
\hline \multirow[t]{2}{*}{$\begin{array}{l}\text { T'ypes } \\
\text { of } \\
\text { r,amp }\end{array}$} & \multicolumn{2}{|c|}{ Input Current } & \multicolumn{2}{|c|}{$\begin{array}{l}\text { Input Power } \\
\text { (Watt) }\end{array}$} & \multicolumn{2}{|c|}{$\begin{array}{l}\text { Voltage } \mathrm{THD} \\
\text { (total harmonic } \\
\text { distortion), } \%\end{array}$} & \multicolumn{2}{|c|}{ Current THD, \% } \\
\hline & $\begin{array}{l}\text { Mag. } \\
\text { Ballast } \\
(\mathrm{mA})\end{array}$ & $\begin{array}{l}\text { Elec. } \\
\text { Ballast } \\
\text { (A) }\end{array}$ & $\begin{array}{l}\text { Mag. } \\
\text { Ballast }\end{array}$ & $\begin{array}{l}\text { Elec. } \\
\text { Ballast }\end{array}$ & $\begin{array}{l}\text { Mag. } \\
\text { Ballast }\end{array}$ & $\begin{array}{l}\text { Élec. } \\
\text { Ballast }\end{array}$ & $\begin{array}{l}\text { Mag. } \\
\text { Ballast }\end{array}$ & $\begin{array}{l}\text { Elec. } \\
\text { Ballast }\end{array}$ \\
\hline A1 & 551.66 & 3.45 & 46.348 & 41.40 & 51.44 & 6.40 & 6.94 & 5.189 \\
\hline$A^{2}$ & 542.03 & 3.28 & 46.095 & 39.36 & 51.15 & 6.61 & 6.78 & 5.151 \\
\hline B & 527.46 & 3.55 & 49.020 & 42.6 & 44.88 & 6.10 & 6.58 & 5.409 \\
\hline $\mathrm{C}$ & 545.46 & 3.43 & 46.235 & 41.16 & 54,37 & 6.37 & 6.70 & 5.472 \\
\hline
\end{tabular}

Table 2 Lamp characteristic for Magnetic (supply voltage 220 V, $50 \mathrm{~Hz})$ and DC Electronics $(12 \mathrm{~V}, 41 \mathrm{kHz})$ ballast

\begin{tabular}{|c|c|r|r|r|l|l|}
\hline \multirow{2}{*}{$\begin{array}{l}\text { Types of } \\
\text { Lamp }\end{array}$} & \multicolumn{2}{|l|}{$\begin{array}{l}\text { RMS Lamp voltage } \\
\text { (V) }\end{array}$} & \multicolumn{2}{l|}{$\begin{array}{l}\text { RMS Lamp current } \\
(\mathrm{mA})\end{array}$} & $\begin{array}{l}\text { Light Output } \\
\text { (Lumen) }\end{array}$ \\
\cline { 2 - 7 } & $\begin{array}{l}\text { Mag. } \\
\text { Ballast }\end{array}$ & $\begin{array}{l}\text { Elec. } \\
\text { Ballast }\end{array}$ & $\begin{array}{l}\text { Mag. } \\
\text { Ballast }\end{array}$ & $\begin{array}{l}\text { Elec. } \\
\text { Ballast }\end{array}$ & $\begin{array}{l}\text { Mag. } \\
\text { Ballast }\end{array}$ & $\begin{array}{l}\text { Elec. } \\
\text { Ballast }\end{array}$ \\
\hline A1 & 77.45 & 76.96 & 557 & 514 & 3980 & 3550 \\
\hline A2 & 77.26 & 80.30 & 568 & 416 & 3790 & 3304 \\
\hline B & 88.86 & 84.03 & 530 & 408 & 4000 & 3354 \\
\hline C & 71.45 & 80.41 & 533 & 483 & 3600 & 3320 \\
\hline
\end{tabular}

Table 3 Efficacy and inverter efficiency

\begin{tabular}{|c|l|c|c|c|c|}
\hline \multirow{2}{*}{$\begin{array}{c}\text { Type of } \\
\text { Lamp }\end{array}$} & \multicolumn{2}{|l|}{$\begin{array}{l}\text { Efficacy1* } \\
\text { (Lumen/watt) }\end{array}$} & \multicolumn{2}{l|}{$\begin{array}{l}\text { Efficacy2 } \\
\text { (Lumen/watt) }\end{array}$} & $\begin{array}{l}\text { Inverter Efficiency } \text { n (Lamp } \\
\text { input Power/Input DC Power) \% }\end{array}$ \\
\cline { 2 - 6 } & $\begin{array}{l}\text { Mag. } \\
\text { Ballast }\end{array}$ & $\begin{array}{l}\text { Elec. } \\
\text { Ballast }\end{array}$ & $\begin{array}{l}\text { Mag. } \\
\text { Ballast }\end{array}$ & $\begin{array}{l}\text { Elec. } \\
\text { Ballast }\end{array}$ & Electronic Ballast \\
\hline A1 & 85.87 & 85.74 & 112.16 & 92.045 & 93.15 \\
\hline A2 & 82.22 & 83.94 & 104.30 & 93.565 & 89.71 \\
\hline B & 81.6 & 78.739 & 100.93 & 90.88 & 86.63 \\
\hline C & 77.86 & 80.66 & 101.79 & 94.41 & 85.36 \\
\hline
\end{tabular}

*Efficacy1 = Lamp output in lumen/Input power in watt.

**Efficacy2 = Lamp output in lumen/Lamp power in watt. case of magnetic ballast are found eight times larger than that of dc electronic ballast. Furthermore the total current harmonics of magnetic ballast is higher than that of the dc electronic ballast.

The other lamp parameters were measured using an integrating sphere of 2.5 meter diameter, a digital power meter and a digital multimeter. The experiment was done similarly with magnetic ballast and with dc electronic ballast. The experimental data are shown in Table 2 and Table 3.

From Table 2 and 3 it is clear that total light output with magnetic ballast is more for each case but Efficacy 1 is higher with dc electronics ballast for two lamps $\mathrm{A} 2$ and $\mathrm{C}$, though for $\mathrm{B}$ it is lower and for $\mathrm{A} 1$ it is almost same. For different lamps, Efficacy 2 of dc electronic ballast varied from $82.065 \%$ (for Lamp A1) to $92.75 \%$ (for lamp C) of that of magnetic ballast. The inverter efficiency is found very high ranging from $85.36 \%$ (for lamp C) to $93.15 \%$ (for lamp A1). It is clear that inverter efficiency depends on the SOX lamp characteristics because all the lamps have been tested with the same developed inverter power circuit and control circuit.

\section{SPVA selection and battery specification}

To select the SPVA and battery size, considering 11 hours run time in the night maximum consumption of Ampere Hour $(\mathrm{AH})$ with dc electronic ballast has been taken as $3.55 \times 11=39.05 \mathrm{AH}$.

It is assumed that in eastern India about $8 \mathrm{AH}$ daily charging is available from an SPVA rated for 35 watt peak ( $35 \mathrm{WP}$ ) solar panel and so the SPVA used for $35 \mathrm{~W}$ lamp would be rated at $200 \mathrm{WP}$. Considering $70 \%$ dis- $^{-}$ charging battery rating for 35 watt SOX, it would be $39.08 / 0.7=55.78 \mathrm{AH}$ for one day. If 3 days autonomy is required, the battery rating would be $55.78 \times 3=167.34$ $\mathrm{AH}$, so we may use $160 \mathrm{AH}$ battery.

\section{Conclusion}

In this developed system, the major parts involving high capital costs are the SPVA and the storage battery. The other components of the system are easily available in the rural market also and cost of the components is very low. In rural or remote areas technicians can easily assemble or repair the circuit. While it is known that the use of a micro controller or an SG 3524 instead of a TL 494 as the inverter drive generator would have eliminated the extra discrete components and the associated real-estate cost of the printed circuit board, the use of the former was avoided in view of the easier availability and much lesser cost of the latter.

Owing to the use of low-cost and appropriate technology, the proposed system is likely to generate employment opportunities for the rural technicians. This 
system can be used not only for lighting in rural or remote areas but also may be used in some industrial application or high way lighting. As the system efficacy has been found more than the conventional system, due to less consumption of electrical energy, this will save the coal and oil reserves, produce less pollutants and thereby make the environment green and eco-friendly.

Use of the proposed circuit fitted in proper luminaire in the roadways, jetties, forest path ways and sea shores will help all the passerby, fishermen and sailors to easily understand their destinations clearly in foggy weather. The mortality rate during the night will decrease owing to lesser occurrence of snake bites, wild animal attacks and other accidents.

\section{References}

(1) Mazumdar, S., Kalyankumar, R., Golder, S. and Sur, A.: An Energy Effficient Solar Exterrior Lighting System with Timer-controlled Dimming Facility, 25th Session of the CIE-sandiego-25 June-2 July 2003, International Conference proceeding, Vol.2, pp.D5. 28-31.

(2) URL : http://www.lamptech.co.uk/Documents/SO4\% 20History\%20LV.htm

(3) Cayless, M. A. and Marseden, A. M. ed.: Lamps and Lighting, Edward Arnold Publishers Ltd., Third Edition (1983).

(4) Narisada, K. and Schreuder, D.: Light Pollution Hand Book, Springer (2004).

(5) CMOS Data book, Intersil, USA. 